\title{
Collaborative Learning Problems and Identity Salience: A Mixed Methods Study
}

\author{
Feihong Wang \\ John K. Burton \\ Virginia Polytechnic Institute and State University
}

\begin{abstract}
Peer collaborative learning that emphasizes collaboration among peers has attracted a great deal of interest since the last two decades of the 20 ${ }^{\text {th }}$ century (Dornyei, 1997; Martin, 2007). Other than proved academic advantages, many collaborative groups were ineffective and failed to generate any collaborative actions (Hardy, Lawrence, \& Grant, 2005; Johnson \& Johnson, 1996). Identities are motivators of human actions (Stryker, 1968), which impact students'behavior tendencies to be contributing or preventing to the occurrence of the collaborative learning problems. The purpose of this study was to explore students' behavioral tendencies in dealing with collaborative learning problems in relation to their identity salience. A total of 17 graduate students were selected from 143 survey participants to participate in in-depth interviews. This study applied a sequential, mixed methods design with the participant selection model (Creswell \& Plano-Clark, 2007). Results of the study disclosed the relationship between students' identity salience and their behavioral tendencies in dealing with collaborative learning problems: group tension, the free-rider effect, and role taking.
\end{abstract}

Keywords: collaborative learning, identity salience, free-rider effect, group tension, role taking

\section{Introduction}

Collaborative learning has attracted a great deal of interest since the last two decades of the 20th century (Dornyei, 1997; Martin, 2007). Other than its proved academic advantages, collaborative learning also faces skepticism for its transient quality (Thomas \& Perry, 1998; 2006). The failure of a collaborative learning activity can be attributed mainly to three collaborative learning problems: group tension (Smith, 2005), perceived group status (Barron, 2003; Nuthall, 1999), and social loafing (Salomon \& Globerson, 1989). Social loafing is the reduction of individual effort when performing collectively (Karau \&
Williams, 1993; Latane, Williams, \& Harkins, 1979). This phenomenon is often accompanied with the free-rider effect, in which one or two students avoid making efforts to complete the group task but take the credit for the group work (Johnson \& Johnson, 1993; Karau \& Williams, 1993; Slavin, 1990). The free-rider effect may eventually let a collaborative learning activity go against its purpose- participating and learning for all group members. To avoid these collaborative learning problems, researchers suggested conditions for effective collaborative learning such as mutuality, interdependence, and equality among group members (Damon \& Phelps, 1989; Dillenbourg, Baker, Blaye, \& O’Malley, 1996; Granott, 1993; Hardy, et al., 
2005; Ozmantar, 2005; Slavin, 1996; Suzuki \& Kato, 1997). However, the fundamental factors that cause these problems were rarely explored.

Researchers have started to investigate collaborative learning through the prism of identity in recent years. Identity salience theory is one of the identity theories that have been explored. Identity salience theory claims that there are three types of identity salience: individual, relational, and collective identity salience (Brewer \& Gardner, 1996; Kashima \& Hardie, 2000; Sluss \& Ashforth, 2007). Identity salience impacts people's motivation, judgment, self-esteem, and behavioral tendencies (Benson \& Mekolichick, 2007; Brewer \& Gardner, 1996; Kashima \& Hardie, 2000). Therefore, students' behaviors may be preventing or contributing to the occurrence of collaborative learning problems under the influence of identity salience.

This study reviewed the concepts of peer collaborative and identity salience, stated the study's purpose and scope, investigated participants' behavioral tendencies in dealing with collaborative learning problems from the perspective of identity salience, and discussed the findings and the future applications.

\section{Review of Literature}

\subsection{Collaborative Learning}

Collaborative learning is defined as "the instructional use of small groups so that students work together to maximize their own and each other's learning" (Johnson \& Johnson, 1996, p. 786). Under this definition category, collaborative learning was defined and adopted differently by researchers based on their specific perspectives (Resta \& Laferriere, 2007). Various variables have been used to differentiate collaborative learning such as time (Johnson \& Johnson, 1996), structure
(Damon \& Phelps, 1989; Fawcett \& Garton, 2005; Goos, Galbraith, \& Renshaw, 2002), and technology involvement (Koschmann, 1994; Pea, 1994). For example, Johnson and Johnson used time to differentiate collaborative learning. According to them a collaborative learning activity that lasts from one class period to several weeks is a formal collaborative learning experience, while an activity that lasts from a few minutes to one class period is an informal collaborative learning experience. This specific study focused on face-to-face, formal, peer collaborative learning.

Most studies on collaborative learning take constructivism, especially theories from Piaget and Vygotsky, as the theoretical underpinning of peer collaborative learning (Dillenbourg, et al., 1996; Fawcett \& Garton, 2005; Tudge, 1992), because they focus on making meaning through social interactions (John-Steiner \& Mahn, 1996). Other than these two theories, this study also attached specific importance to Mead's social act theory for it covers both research variables: identity and collaborative learning. Social act theory is a subdivision of the social learning theory that claims people learn from one another and learning as a result of social interactions (Cronk, 2005; Khan \& Cangemi, 1979; Ormrod, 1999). This theory also takes social group life as the essential condition for the emergence of consciousness, the mind, and the conception of self (Mead, 1934)- the identity.

Scholars of collaborative learning believed that collaborative learning can help students accomplish tasks that cannot be accomplished individually, by leveraging knowledge, skills, and resources between participants, as well as creating circumstances for participants to help each other (Hardy, et al., 2005) and con-construct knowledge (Vygotsky, 1978). Although most studies have proved the positive effects of collaborative learning (e.g., 
Alavi, 1994; Barron, 2000; Bruffee, 1999; Dillenbourg, et al., 1996; Gokhale, 1995; Johnson, Johnson, \& Stanne, 1989; Lochhead, 1985; Schamber \& Mahoney, 2006; Shibley \& Zimmaro, 2002; Slavin, 1999; Waite \& Davis, 2006), not all collaborative learning activities were successful. Many collaborative groups were ineffective and failed to generate any collaborative action (Hardy, et al., 2005; Johnson \& Johnson, 1996). Researchers criticized the transient quality of collaborative learning (Thomson, 2006) and claimed that "collaboration is like cottage cheese. It occasionally smells bad and separates easily" (Thomas \& Perry, 1998, p. 409).

Researchers indicated that the failure of collaborative learning activities was mostly attributed to perceived group status (Barron, 2003; Nuthall, 1999), social loafing (Salomon \& Globerson, 1989), and group tension (Smith, 2005). To avoid these problems, researchers claimed three distinctive and interrelated conditions for effective collaborative learning: mutuality, positive interdependence, and equality (Damon \& Phelps, 1989; Dillenbourg, et al., 1996; Granott, 1993; Hardy, et al., 2005; Ozmantar, 2005; Slavin, 1996; Suzuki \& Kato, 1997). Although researchers have pointed out the conditions for effective collaborative learning, the factors that lead to the problems of collaborative learning were still left untouched. Looking into these questions can help instructional designers and practitioners diagnose collaborative learning problems, bypass pitfalls, and increase effectiveness of collaborative learning activities.

\subsection{Identity}

The crux of social identity theory is the notion that individuals' identities contain both personal and social components (Banaji \& Prentice, 1994; Bettencourt, 1999; Cote \& Levine, 2002; Fearson, 1999; Turner, 1982).
Gergen (1971) specified the structure of identity by two classes of self-conceptions: an individual's membership of various social groups and an individual's specific personal attributes. Turner (1982), later, defined these two classes of self-conceptions as personal identity and social identity. Brewer and Gardner (1996) described two levels of social identity, "those that derive from interpersonal relationships and interdependence with specific others, and those that derive from membership in larger, more impersonal collectives or social categories" (Brewer \& Gardner, 1996, p. 89). That is, social identity could be further divided into relational identity and collective identity (Brewer \& Gardner, 1996; Kashima \& Hardie, 2000; Lord, Brown, \& Freiberg, 1999; Sluss \& Ashforth, 2007). Given together, researchers claimed that an individual's self-conception is composed of three aspects: individual, relational, and collective identity.

Stryker and Burke (2000) suggested that an individual's identity has multiple role-related identity components. These components are organized in a hierarchical order, and they should not be at the same salient level at any given time, otherwise it would result in distress and conflict (Burke, 2003; Stryker, 1968; Stryker \& Burke, 2000). Combining Stryker and Burke's identity theory with the three identity aspect theory, it suggests that three identity aspects are organized in a hierarchical order (Brewer \& Gardner, 1996; Sluss \& Ashforth, 2007) or restrainedly with only one identity aspect takes the dominant position for a person in a given situation (Lord, Brown, \& Freiberg, 1999) - the identity salience. There are three types of identity salience: individual, relational, and collective identity salience (Brewer \& Gardner, 1996; Kashima \& Hardie, 2000; Sluss \& Ashforth, 2007).

Identities are motivators of human actions (Stryker, 1968). Different aspects of identity 
are associated with different social motivations and implications for an individual's self-esteem and behavioral tendencies (Triandis, 1989).

The individual identity salience focuses on oneself as a unique being. The basic motivation is personal self-interest. Relational identity is derived from the connections and role relationships with significant others (Brewer \& Gardner, 1996; Lord, et al., 1999). The relational identity salience is characterized by mutual concern for the interests and outcomes of the other and the self-worth is derived from the appropriate role behavior (Brewer \& Gardner, 1996; Kashima \& Hardie, 2000; Lord, et al., 1999). Collective identity addresses the "we-ness" of a group (Hardy, et al., 2005). The basic motivation for collective identity salience people is the welfare of the group as whole, which places a premium on the common fate, group cohesion, and group norms (Brewer \& Gardner, 1996; Kashima \& Hardie, 2000; Lord, et al., 1999)

\subsection{Identity Salience and Collaborative Learning}

Because identity salience's potential impacts on people's motivation, judgment, selfesteem, and behaviors (Benson \& Mekolichick, 2007; Breckler \& Greenwald, 1986; Brewer \& Gardner, 1996; Kashima \& Hardie, 2000; Triandis, 1989), using identity salience as a prism to analyze problems of collaborative learning may possibly help researchers and practitioners avoid these problems. For example, the individual identity salience orients towards one's own interests and profit (Brewer \& Gardner, 1996; Kashima \& Hardie, 2000; Lord, et al., 1999). Logically, the individual identity salience student may, possibly, become the free rider when the group work conflicts with his/her own benefits.
The purpose of this study was to explore participants' behavioral tendencies in dealing with three collaborative learning problems, group tension, the free-rider effect, and role taking, from the perspective of identity salience. The merging of quantitative and qualitative data of this study happened through the data collection, data analysis, and discussion phases. This study was guided by the following three research questions with each focuses, specifically, on one or more collaborative learning problems:

Qualitative 1: How do students deal with group tension in relation their identity salience? (Communication, Group tension) Qualitative 2: How do students deal with the free-rider effect in relation to their identity salience? (The free-rider effect) Qualitative 3: How do students take a specific role (leader, coordinator, and follower) in collaborative learning in relation to their identity salience? (Group tension)

\section{Method}

\subsection{Study Design}

This study used a two-phase, sequential, mixed methods explanatory research design with a participant selection model, in which the data mixing occurred through connecting quantitative and qualitative datasets (Creswell, 2003; Creswell \& Plano-Clark, 2007). In phase I, a survey was used to identify participants' identity salience. In phase II, interviews were conducted to explore participants' experiences of collaborative learning problems at the intraindividual level.

\subsection{Research Participants}

The study's population consisted of current graduate students in the School of Education at Virginia Tech. A total of 143 students completed 
the survey $($ male $=41 \%$, female $=59 \%$, and 17 participants were selected purposefully to participate in the interviews. The 17 interview participants consisted of 6 individual identity salience students, 6 relational identity salience students, and 5 collective identity salience students.

The selected participants met four requirements. First, they left contact information indicating their willingness to participate in the follow-up interview at the end of the survey. Second, they confirmed their willingness to participate in the face-to-face interview through email with the researchers after the completion of the survey data analysis. Third, the participants' locations were within one-hour driving distance from Virgin Tech. Last, the researchers tried to have even sample percentage from each identity salience group.

\subsection{Data Collection Procedure}

The questionnaire was distributed in two ways: via school email listservs and in classes. The participant recruitment letter was sent out through two of the School of Education email listservs to include students enrolled on the main campus and students enrolled at the off-campus locations. The recruitment letter provided preliminary information about the study and included the URL to the electronic questionnaire. In addition to recruit students via listservs, the researchers also contacted five graduate instructors to get their consent to recruit participants in their classes. After the researchers introduced the study in the class, both the instructor and the researchers exited the classroom. The researchers collected the survey after all students left the classroom.

After the quantitative data was collected, processed, and analyzed, the researchers selected and interviewed 17 participants in a secure setting on campus. Each participant was interviewed by following the interview protocol. Each interview lasted approximately 30 minutes. A digital audio-recording device recorded participants' responses. The recorded interview was transcribed verbatim shortly after each interview.

\subsection{Survey Instrument}

This study adapted Kashima and Hardie's (2000) RIC-scale to measure participants' identity salience. The RIC-scale consists of ten items, each followed by three response items corresponding to relational, individual, and collective selves. For each question, the participants were required to choose only one of the three response items. For example, the question asked "I think it is most important in life to .", the three following responses were "Have personal integrity/be true to myself" (indicates individual identity aspect); "Have good personal relationships with people who are important to me" (indicates relational identity aspect); "Work for causes to improve the well-being of my group" (indicates collective identity aspect). Participants might think more than one or all of these three responses were important, they could only choose the one that most closely represented their ideas. The monomial choice among the three responses indicated participants' identity aspects and the maximum answers for the ten questions indicated the participant's overall identity salience.

This study adopted the Kashima and Hardie RIC-scale for two reasons. First, the purpose and the content of the RIC-scale instrument were completely consistent with the requirements of this study. Second, Kashima and Hardie went through eight sets of different scales that were relevant to the three self aspects to develop and test this scale. This approach ensured the validity and reliability of the instrument. 


\subsection{Interview Protocols and Coding}

The interview protocols were formulated by the researchers under the guidance of the research questions. The interview had seven protocols. The protocol first addressed more general concerns such as students' perceptions of collaborative learning and experience of prior collaborative learning activities. Protocol questions then probed more deeply by asking questions about students' priorities in collaborative learning.

The data analysis process took six rounds. In round one, each transcript was coded according to the research questions. For example, in a transcription, any sections that talked about group tension were highlighted in red while sections that talked about the freerider effect were highlighted in green. Next, all the codes from round one were copied and pasted into a separate coding sheet and organized according to the research questions. For example, responses to group tension were put together and organized based on the identity salience groups, as were the responses to the free-rider effect. In round three, codes were compared and summarized to develop a database of common traits as standard codes for each research question. In round four, all the codes from round two were coded again based on the code database developed in round three. In round five, common categories and major themes were identified based on the number of common recurrences. After themes were identified, each transcript was reviewed a final time for the findings.

\section{Results}

\subsection{Research Question 1: Group Tension and Identity Salience}

In this question, it was assumed that the participants had conflicts with another group member in terms of the direction of the group project. In this situation, most of the individual identity salience and relational identity salience participants specified their first inclination to follow most group members' joint choice, whereas no collective identity salience participants chose to do so. That is, the individual identity salience and relational identity salience participants preferred to have other group members involved to address the group tension. For example, one participant said:

I will probably ask other group members and see how they feel and like what they feel more comfortable. What they feel, what they think, which one they think is better. Whatever the group says, we will do it. That's fine (Participant 9).

When the researchers specified the situation as one-on-one situation, the relational identity salience and collective identity salience participants indicated an intention to give up their stance when the other idea was acceptable. Some participants believed that it was not worth to fight. Other than "not worth fighting," "do not like conflicts" was another frequently used reason by the relational identity salience participants. The individual identity salience participants, on the contrary, chose to stop working collaboratively, asked the instructor to intervene, or reduced their efforts instead of giving up their stance.

Concerning the second situation in which other group members got into conflicts, most of the participants chose to intervene in the situation, especially the collective identity salience participants $(100 \%)$. For those $(n=3)$ who chose not to intervene, two participants mentioned a lack of confidence and one mentioned the disinclination to get in the middle of conflicts. 


\subsection{Research Question 2: The Free-rider Effect and Identity Salience}

Participants indicated six possible approaches that they used or would use to deal with free riders in their collaborative group, including asking the instructor to intervene, confronting the free riders directly, making up the group work, assigning specific tasks to the free rider, marginalizing free riders' work during the presentation, and making up the work with other group members. Most participants expressed their tendencies to make up the group work. Among them, the individual identity salience participants had a stronger propensity to ask the instructor to intervene in the free-rider situation and to confront the free riders directly than participants from the relational and collective identity salience groups. An individual identity salience participant believed that, "The instructor probably has experienced it before. And make [sure] she knows [that], some ways, I couldn't help motivate the group members, so that is why [I go to the instructor]. I always go to the instructor first" (Participant 1).

On the contrary, the relational identity salience participants clearly indicated their disinclination to get the instructor involved in addressing the free-rider issues. One relational identity salience participant stated:

It is difficult, as a graduate student, to want to approach the professor, because I feel like it shows a lack of skills on our part as a group. So I am always hesitant to go to talk to a professor about it (Participant 9).

In addition to being reluctant to ask the instructor to intervene in the free-rider situation, the relational identity salience participants also expressed their hesitation to confront the free riders directly. They stated: "I think, I just won't want to damage that relationship" (Participant
9), and "I am not a confrontational person at all" (Participant 7).

Similar to the relational identity salience participants, the collective identity salience participants also chose not to confront free riders directly. However, their no-confrontation principle did not come from the standpoint of maintaining the group harmony, but depending on whether the free-rider effect would become a long term issue:

If I knew if someone is gonna to be seen every day for the next 20 years, something like that, then I would say "hi, we need to come with some sort of arrangement". But in the short time span, it just wouldn't be worth to me to confront the person and trying to get things done (Participant 12).

Instead of direct confrontation, some relational and collective identity salience participants chose to assign specific tasks to the free riders. The collective identity salience participants believed: "Usually, when you make the person responsible for one thing, they usually get much better in terms of participating" (Participant 11).

\subsection{Research Question 3: Role Taking and Identity Salience}

In order to find out how role taking in collaborative groups was related to students' identity salience, the researchers asked participants about their roles in prior collaborative learning activities and the circumstances under which they took the specific roles. Among the three identity salience groups, participants from the collective identity salience group showed the strongest leadership tendency. A collective identity salience participant stated, "I am usually the leader, or even if I am not, I come to be" (Participant 2). Another participant 
stated "I would say, in most situations, I tend and want to be the leader, unless there is other people step up and do it" (Participant 4).

According to the participants, three reasons contributed to their taking of the leader's role in collaborative learning settings: personality, prior knowledge, and willingness to work hard. The relational and collective identity salience students indicated "prepared with plan" as an important reason and an effective strategy for becoming a group leader. One of them stated, "I will always bring a plan. I always have a plan. I am ok if we change it, but I always have something to go from" (Participant 9).

Two individual identity salience students indicated their desire to be group leaders in small groups, groups with two to four group members. They wanted to become group leaders because they believed that being group leaders gave them better control of their grades. As one participant stated, "I don't want my grade to suffer" (Participant 14).

Few participants indicated their experience or desire of being a follower. Participants stated that being a subject matter expert or knowing most of the subject among peers was the determinant for taking the leader's role. For example, one participant stated, "because I am not the subject matter expert in the area, I cannot do the job as the leader" (Participant 17). In addition to that, students who work for their master's degree were more likely to take the follower's role when working with doctoral students.

\section{Discussion}

Guided by the three research questions, the researchers explored participants' ways of dealing with collaborative learning problems. The relational identity salience participants' responses to questions reflected their values on group relationships and interdependence as predicted by Markus and Kitayama (1991). When getting involved in conflicts with another group member, the relational identity salience students tended to refer to the rest of the group members for the final decision; otherwise, they tended to give up their stance in order to avoid the group tension. "Do not like conflicts" or "do not want to damage relationship" were often the reasons for their decisions. For the same reason, the relational identity salience students tended to make up the group work without instructors' intervention or confrontation to the free riders, when caught up in the free-rider situation.

The collective identity salience participants showed the strongest leadership tendency among the groups. Some of collective identity salience students brought project plans to their group meetings as a strategy to ensure their leadership of the group. The collective identity salience participants were, to some extent, consistent with what they were predicted - they placed a premium on the success of the group (Brewer \& Gardner, 1996; Kashima \& Hardie, 2000; Lord, et al., 1999). For example, when getting involved in group conflicts, they might give up their stance when the other student's idea was acceptable. However, they are less likely to consider consulting with the rest of the group members for the final decision. They might use strategies or, sometimes, direct confrontations to get work done in the ways that they thought were the best. When facing the free-rider situation, they normally would not confront the free riders directly, but assign them specific tasks. If the free riders still chose to not pull their weight, the collective identity salience students would make up the group work instead of confronting them directly.

The individual identity salience participants had comparatively less confidence and strategies to deal with problems in 
collaborative learning. When facing free riders, the individual identity salience participants had a stronger propensity to ask for the instructor to intervene and to confront the free riders directly. Their decisions were based on more self-interest oriented reasons than the relational and collective identity salience participants. For example, when they had conflicts with the other group member, especially in one-on-one situation, they tended not to give up their stance easily. They may stop collaborating and rely on the instructor to solve the problem, or reduce their personal efforts in group work. Some individual identity salience students wanted to be group leaders in small groups for getting better control of their grades. In addition, only the participants in the individual identity salience group admitted to the possibility of being free riders.

This study contributed to the understanding of the possible influences of identity salience on students' reactions to collaborative learning problems. Findings of this study can bring insights into the learner analysis for instructional designers to design better collaborative learning activities. Second, findings of this study can also help instructors to predict their students' possible behaviors in collaborative learning activities. Eventually, instructors can facilitate collaborative learning better. At last, this study was the preliminary exploration on peer collaborative learning from the prism of students' identity salience. It laid the ground for future research of its kind.

Albeit its contributions, this study was not without limitations. First, the study could not guarantee the honesty of all responses. The accuracy and completion of interview information relies on the willingness of the respondents (Breakwell, Hammond, \& Fife-Schaw, 1995). As Patton (2002) listed, "interview data limitations include possibly distorted responses due to personal bias, anger, anxiety, politics, and simple lack of awareness" (p. 306). Second, the participants were asked to base their answers on their personal experiences at the beginning of the interview. However, many answers were still based on participants' assumptions of what they might do due to their limited collaborative learning experiences. Finally, the researchers were the only data collection instrument in the interviews. The researchers also took the exclusive responsibility for data transcription, coding, and reporting. This being the case, the researchers' personal biases might have affected any phases of the study.

This study also provided topics for future research inquiries. First, from the discussion of the findings, it is clear that students' identity salience should be taken into consideration when grouping students for collaborative learning. For future instructional applications, experimental studies could be conducted to examine how students with different identity salience should be grouped to conduct an effective collaborative learning activity. Second, some of the interview findings can be conveyed to a survey with the purpose of generalizing the interview findings to a larger group. Third, this study only focused on students who majored in education. Students from other majors could also be investigated.

\section{References}

Alavi, M. (1994). Computer-mediated collaborative learning: An empirical evaluation. MIS Quarterly 18(2), 159-174.

Banaji, M. R., \& Prentice, D. A. (1994). The self in social contexts. Annual Review of Psychology, 45(1), 297-332. 
Barron, B. (2000). Achieving coordination in collaborative problem-solving groups. The Journal of the Learning Sciences, 9(4), 403-436.

Barron, B. (2003). When smart groups fail. The Journal of the Learning Sciences, 12(3), 307-359.

Benson, D. E., \& Mekolichick, J. (2007). Conceptions of self and the use of digital technologies in a learning environment. Education, 127(4), 498-510.

Bettencourt, B. A. (1999). The cognitive contents of social-group identity: Values, emotions, and relationships. European Journal of Social Psychology, 29(1), 113-121.

Breakwell, G. M., Hammond, S., \& Fife-Schaw, C. (1995). Research methods in psychology. London: Sage.

Brewer, M. B. (1991). The social self: On being the same and different at the same time. Personality and Social Psychology Bulletin, 17(5), 475-482.

Brewer, M. B., \& Gardner, W. (1996). Who is this "we"? Levels of collective identity and self representations. Journal of Personality and Social Psychology, 71(1), 83-93.

Bruffee, K. A. (1999). Collaborative learning: Higher education, interdependence, and the authority of knowledge. Baltimore: John Hopkins University Press.

Burke, P. J. (2003). Relationships among multiple identities. In P. J. Burke, T. J. Owens, R. Serpe \& P. A. Thoits (Eds.), Advances in identity theory and research (pp. 199-214). New York: Kluwer.

Cote, J. E., \& Levine, C. G. (2002). Identity formation, agency, and culture: A social psychological synthesis. Mahwah, New Jersey: Lawrence Erlbaum.

Creswell, J. W. (2003). Research design: Qualitative, quantitative, and mixed methods approaches. Thousand Oaks: Sage.

Creswell, J. W., \& Plano-Clark, V. L. (2007). Designing and conducting: Mixed methods research. London: Sage.
Cronk, G. (2005). George Herbert Mead (1863-1931). The internet encyclopedia of philosophy Retrieved November, 19, 2008, from http://www.iep.utm.edu/m/mead.htm

Damon, W., \& Phelps, E. (1989). Critical distinctions among three approaches to peer education. International Journal of Educational Research, 13(1), 9-19.

Dillenbourg, P., Baker, M., Blaye, A., \& O'Malley, C. (1996). The evolution of research on collaborative learning. In E. S. P. Reiman (Ed.), Learning in humans and machine: Towards an interdisciplinary learning science (pp. 189-211). Oxford: Elsevier.

Dornyei, Z. (1997). Psychological processes in cooperative language learning: Group dynamics and motivation. The Modern Language Journal, 81(4), 482-493.

Fawcett, L. M., \& Garton, A. F. (2005). The effect of peer collaboration on children's problem-solving ability. British Journal of Educational Psychology, 75(2), 157-169.

Fearson, J. D. (1999). What is identity. Unpublished Draft. Stanford University.

Gergen, K. J. (1971). The concept of self. New York: Holt, Rinehart, and Winston.

Gokhale, A. A. (1995). Collaborative learning enhances critical thinking. Journal of Technology Education, 7(1), 22-30.

Goos, M., Galbraith, P., \& Renshaw, P. (2002). Socially mediated metacognition:

Creating collaborative zones of proximal development in small group problem solving. Educational Studies in Mathematics, 49(2), 193-223.

Granott, N. (1993). Patterns of interaction in the co-construction of knowledge: Separate minds, joint effort, and weird creatures. In R. H. Wozniak \& K. W. Fischer (Eds.), Development in context: Acting and thinking in specific environment (pp. 183207). Hillsdale, NJ: Lawrence Erlbaum

Hardy, C., Lawrence, T. B., \& Grant, D. (2005). Discourse and collaboration: The role 
of conversations and collective identity. Academy of Management Review, 30(1), 58-77.

John-Steiner, V., \& Mahn, H. (1996). Sociocultural approaches to learning and development: A Vyotskian framework. Educational Psychologist, 31(3/4), 191-206.

Johnson, D. W., \& Johnson, R. T. (1993). Cooperative learning and feedback in technology-based instruction. In J. V. Dempsey \& G. C. Sales (Eds.), Interactive instruction and feedback. Englewood Cliffs, New Jersey: Educational Technology Publications.

Johnson, D. W., \& Johnson, R. T. (1996). Cooperation and the use of technology. In D. H. Jonassen (Ed.), Handbook of research for educational communications and technology (pp. 785-812). New York: Simon and Schuster.

Johnson, D. W., Johnson, R. T., \& Stanne, M. (1989). Impact of goal and resource interdependence on problem-solving sucess. Journal of Social Psychology, 129(5), 621-629.

Karau, S. J., \& Williams, K. D. (1993). Social Loafing: A meta-analytic review and theoretical integration. Journal of Personality and Social Psychology, 65(4), 681-706.

Kashima, E. S., \& Hardie, E. A. (2000). The development and validation of the relational, individual, and collective self aspects (RIC) scale. Asian Journal of Social Psychology, 3(1), 19-48.

Khan, K. H., \& Cangemi, J. P. (1979). Social learning theory: The role of imitation and modeling in learning socially desirable behavior. Education, 100(1), 41-46.

Koschmann, T. D. (1994). Toward a theory of computer support for collaborative learning. The Journal of the Learning Sciences, 3(3), 219-225.

Latane, B., Williams, K., \& Harkins, S. (1979). Many hands make light the work:
The causes and consequences of social loafing. Journal of Personality and Social Psychology, 37(6), 822-832.

Lochhead, J. (1985). Teaching analytic reasoning skills through pair problem solving. In J. W. Segal, S. F. Chipman \& R. Glaser (Eds.), Thinking and learning skills. Vol. 1: Relating instruction to research (pp. 109-131). Hillsdale, NJ: Erlbaum.

Lord, R. G., Brown, D. J., \& Freiberg, S. J. (1999). Understanding the dynamics of leadership: The role of follower selfconcepts in the leader/follower relationship. Organizational Behavior and Human Decision Processes, 78(3), 167-203.

Markus, H. R., \& Kitayama, S. (1991). Culture and the self: Implications for cognition, emotion, and motivation. Psychological Review, 98(2), 224-253.

Martin, J. (2007). Educating communal agents: Building on the perspectivism of G. H. Mead. Educational Theory, 57(4).

Mead, G. H. (1934). Mind, self \& society. Chicago, Illinois: The University of Chicago Press.

Nuthall, G. (1999). Learning how to learn. International Journal of Educational Research, 31(3), 141-256.

Ormrod, J. E. (1999). Human learning. Upper Saddle River, NJ: Prentice - Hall.

Ozmantar, M. F. (2005). Relational identities in peer collaboration: Self-perceptions, assumed roles and individual tendency Eurasian Journal of Educational Research, 20, 189-202.

Patton, M. Q. (2002). Qualitative research and evaluation methods. Thousand Oaks, CA: Sage.

Pea, R. D. (1994). Seeing what we build together: Distributed multimedia learning environments for transformative communications. Journal of the Learning Sciences, 3(3), 285-299.

Resta, P., \& Laferriere, T. (2007). Technology in support of collaborative learning. 
Educational Psychology Review, 19(1), 65-83.

Salomon, G., \& Globerson, T. (1989). When teams do not function the way they ought to International Journal of Educational Research 13(1), 89-99.

Schamber, J. F., \& Mahoney, S. L. (2006). Assessing and improving the quality of group critical thinking exhibited in the final projects of collaborative learning groups. The Journal of General Education, 55(2), 103-137.

Shibley, I. A., \& Zimmaro, D. M. (2002). The influence of collaborative learning on student attitudes and performance in an introductory chemistry laboratory Chemical Education Research, 79(6), 745-748.

Slavin, R. E. (1990). Cooperative learning: Theory, research, and practice. Englewood Cliffs, NJ: Prentice-Hall.

Slavin, R. E. (1996). Research on cooperative learning and achievement: What we know, what we need to know. Contemporary Educational Psychology, 21(1), 43-69.

Slavin, R. E. (1999). Synthesis of research on cooperative learning. In A. C. O. L. S. BeharHorenstein (Ed.), Contemporary issues in curriculum (pp. 193-203). Needham Heights, MA: Allyn and Bacon.

Sluss, D. M., \& Ashforth, B. E. (2007). Relational identity and identification: Defining ourselves through work relationships. Academy of Management Review, 32(1), 9-32.

Smith, R. O. (2005). Working with difference in online collaborative groups. Adult Education Quarterly, 55(3), 182-199.

Stryker, S. (1968). Identity salience and role performance: The relevance of symbolic interaction theory for family research Journal of Marriage and the Family, 30(4), 558-564.

Stryker, S., \& Burke, P. J. (2000). The past, present, and future of an identity theory. Social Psychology Quarterly, 63(4), 284-297.
Suzuki, H., \& Kato, H. (1997). Identity formation/transformation as the process of collaborative learning through AlgoArena. Paper presented at the CSCL ' 97

Thomas, A. M., \& Perry, J. L. (1998). Can AmeriCorps build communities? Nonprofit and Voluntary Sector Quarterly, 27(4), 399-420.

Thomson, A. M. (2006). Collaboration processes: Inside the Black Box. Public Administration Review, 66(s1), 20-32.

Tudge, J. (1992). Processes and consequences of peer collaboration: A Vygotskian Analysis. Child Development, 63(6), 1364-1379.

Turner, J. C. (1982). Towards a cognitive redefinition of the social group. In $\mathrm{H}$. Tajfel (Ed.), Social identity and intergroup relations (pp. 15-40). Cambridge, England: Cambridge University Press.

Vygotsky, L. (1978). Mind and society: The development of higher psychological processes. Cambridge, MA: Harvard University Press.

Waite, S., \& Davis, B. (2006). Collaboration as a catalyst for critical thinking in undergraduate research Journal of Further and Higher Education, 30(4), 405-419.

\section{Contact the Authors}

Feihong Wang, Ph.D.

Virginia Polytechnic Institute and Sate

University, USA

E-mail: Fwang06@vt.edu

John K. Burton, Ph.D.

Virginia Polytechnic Institute and Sate University, USA

E-mail: jburton@vt.edu 